\title{
Maps of first orienteering events
}

\author{
László Zentai ${ }^{\text {a }}$ \\ ${ }^{a}$ ELTE Eötvös Loránd University, Institute of Cartography and Geoinformatics, Budapest, Hungary - laszlo.zentai@elte.hu
}

Keywords: orienteering map, map use

\begin{abstract}
:
One of the most special characteristics of orienteering maps is that the users (the orienteers themselves) make these maps, since cartographers would not be able to produce good orienteering maps without having very good knowledge on the sport itself. Nowadays, orienteering maps are widely used by the athletes, clubs, sport federations, there are established and widely accepted rules and guidelines, specifications describe all aspects of an orienteering event, especially the maps.

This was very different when this sport started. Although the International Orienteering Federation was established only in 1961, the early beginnings of the sport goes back even to the very late part of the $19^{\text {th }}$ century. Orienteering is originated from military activities, when cadets were trained to use maps for terrain navigation. To make this education more interesting and more challenging, such competitive events were organised. It was quite difficult to define when these events became open for non-military people. Finally the Scandinavian countries (where these activities started) agreed on that the first civil orienteering event was held in 1897 in Norway. Some journals published reports on this event, presented the results, even mentioned the place of control points, but there were no information on which kind of maps were used by the competitors in the event. Map use, map access at that time was totally different than nowadays. Printed maps were already available at the end of $19^{\text {th }}$ century, but the printing itself was quite expensive (particularly in colour), so there was no chance to use special maps for orienteering events. It was already investigated which kind of existing maps were potentially used for those events (tourist map, topographic map, winter sport map).

It was a real surprise to come across an article in an Austrian sport journal one or two years ago which reveals that a bicycle race with map navigation (today we call mountain bike orienteering) was organised in 1893. The 1 October and 15 October 1893 issues of Radfahr-Sport, published in Vienna, reported a new type of competition they called Terrainfahren, which was organised as part of the event of the Bund Deutscher Radfahrer Oesterreichs. The event took place as part of the Gaufest bicycle competitions in the Waldviertel region (Langenlois). It seems that it was an open public event, not a military one. However, there were no information on which maps were used. The large-scale topographic maps of the Third Military Survey or even larger-scale cadastral maps already existed at that time, but they were either classified or not used by civilians or not printed/copied at all (they were only manuscript maps). So it is still unknown which kind of maps were used in this first bicycle orienteering race, although being familiar with the civilian map use of this time we may have some tips.
\end{abstract}

We have slightly better knowledge on the first Swedish orienteering event, which was organised in 1901 . It was a $14 \mathrm{~km}$ long course with four controls. The 1:100,000 scale topographic map was fieldworked sometime between 1845 and 1866 and it was printed in 1873 . 


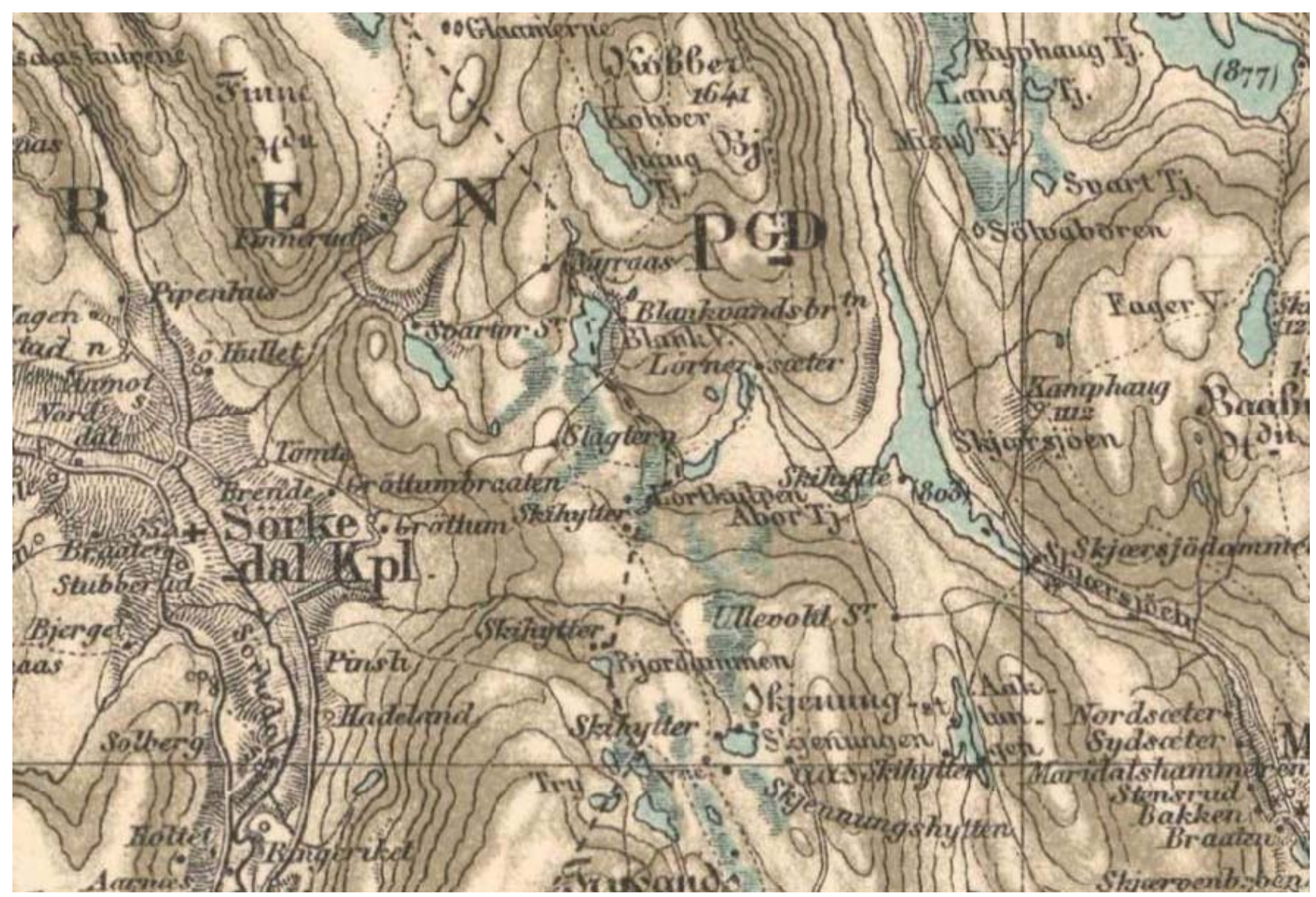

Figure 1. One of the potential maps in the first orienteering event (Norway, 1897).

The first orienteering event in Hungary was organised in 1925. This fact was not known at all when the Hungarian Orienteering Federation was founded in 1970 or even when the first national championships were organised in 1950 (however, it was a different kind of sport at that time). In 1978, an article on orienteering sport was published in a popular weekly political journal (Magyarország) including the history of Hungarian orienteering. Then we thought that the sport had started in Hungary in 1950. The publisher of the journal got several feedback from the readers and all of them stated that they had already participated in orienteering events between the two world wars. Researching in various libraries revealed that the first orienteering event was organised by a former prisoner of war (who came back to Hungary via Sweden after WWI) in 1925. Several journals published a report on the event, even mentioned the places of the control points, but none of them mentioned the map which was used by the competitors. The independent Hungarian national mapping institute was just formed in 1919, but only few modern, contour lined topographic maps were published. Probably a tourist map was used in the event, but we have to take into consideration that whatever kind of map was used, these printed maps sheets was quite expensive at that time.

It is important to be familiar with the map use of earlier times to be able to identify which kinds of maps were available for civilian use. Not too much research was made on the history of map use in the early $20^{\text {th }}$ century. Map use in certain times depended on several factors including political, historical, social factors. Orienteering maps are good examples of special map use. 